\title{
PERAN PEKERJA SOSIAL DALAM MENINGKATKAN KEBERFUNGSIAN SOSIAL LANSIA DI PANTI SOSIAL TRESNA WERDHA BUDHI DHARMA BEKASI
}

\author{
Oleh: \\ Githa Muthia, Hj. Hetty Krisnani, \& Lenny Meilany \\ E-mail: githamuthia@gmail.com
}

\begin{abstract}
ABSTRAK
Penelitian ini bertujuan untuk mengetahui metode pelayanan sosial agar meningkatkan keberfungsian sosial lansia. Informan dalam penelitian ini yaitu lima orang Pekerja Sosial yang bekerja di Panti Sosial Tresna Werdha Budhi Dharma Bekasi. Data yang diperoleh melalui metode dokumentasi dan wawancara dianalisis dengan teknik deskriptif-kualitatif, sedangkan data yang diperoleh melalui metode observasi dan teknik pengumpulan data kuesioner dianalisis dengan teknik deskriptifkuantitatif. Untuk peneliti lain diharapkan dapat mengembangkan penelitian yang telah dilakukan ini agar sistem pelayanan sosial di Panti Sosial lebih relevan untuk memperbaiki kekurangan dan memperoleh hasil yang lebih memuaskan.
\end{abstract}

Kata Kunci : pelayanan sosial, lansia, fungsi sosial, pekerja sosial, panti werdha

\section{ABSTRACT}

This study aims to determine the method of social services in order to improve the social functioning of the elderly. Informants in this study is five Social Worker who works in Social Institutions Tresna Elderly Budhi Dharma Bekasi. Data obtained through the method of documentation and interviews were analyzed with descriptive qualitative technique, whereas data obtained through observation methods and techniques of data collection questionnaires were analyzed with descriptive-quantitative technique. For other researchers are expected to develop research that has been done is that the system of social services in social house more relevant to correct deficiencies and obtain more satisfactory results.

Key Words : social services, elderly, social functioning, social worker, foster care

\section{PENDAHULUAN}

Tertera dalam UU-RI No. 13 tahun 1998 tentang Kesejahteraan Lanjut Usia yang pada hakekatnya berisi Upaya peningkatan kesejahteraan sosial yang bertujuan untuk memperpanjang usia harapan hidup dan masa produktif. Munculnya UU ini sebagai jawaban atas permasalahan lanjut usia di Indonesia dengan bentuk perlindungan hukum dari Negara. Peraturan Pemerintah Republik
Indonesia No. 43 tahun 2004 tentang pelaksanaan upaya peningkatan kesejahteraan sosial lanjut usia pun menjadi payung hukum bagi lanjut usia potensial dan lanjut usia tidak potensial. Pemerintah memberikan perlindungan sosial, bantuan sosial, dan aksesibilitas untuk mendukung terciptanya kesejahteraan sosial lanjut usia. Selain itu, dalam rangka mengamalkan ketentuan yang tertuang dalam UU No. 11 tahun 2009 tentang kesejahteraan sosial khususnya pada bab III 
bagian kesatu bahwa penyelenggaraan kesejahteraan sosial diperuntukkan bagi Penyandang Masalah Kesejahteraan Sosial; dalam penelitian ini yaitu kelompok lanjut usia terlantar.

Adanya populasi Penyandang Masalah Kesejahteraan Sosial (PMKS) yang masih menjadi beban sosial bagi setiap Kabupaten / Kota, baik jumlah maupun kompleksitasnya. PMKS tersebut acapkali tidak dapat melaksanakan fungsi sosialnya secara memadai dan wajar sehingga mengganggu pemenuhan kebutuhan hidupnya, semisal akibat dari kemiskinan, ketelantaran, kecacatan, keterbelakangan, keterasingan, keterbatasan, perubahan lingkungan, serta beberapa masalah sosial yang berdampak signifikan di Indonesia.

Data akurat yang diambil dari Badan Pusat Statistik menunjukkan bahwa jumlah lansia di Indonesia semakin meningkat. Berikut merupakan sumber data yang akan digunakan dalam penelitian ini disajikan dalam Tabel 1.

Tabel 1

Jumlah Penduduk Lanjut Usia di Indonesia

\begin{tabular}{|c|c|c|}
\hline Tahun & $\begin{array}{c}\text { Jumlah Penduduk } \\
\text { Tua }\end{array}$ & $\%$ \\
\hline 1970 & 5,3 juta jiwa & 4,48 \\
\hline 1990 & 12,7 juta jiwa & 6,29 \\
\hline 2010 & 23 juta jiwa & 10 \\
\hline $\begin{array}{c}2020 \\
\text { (prakiraan) }\end{array}$ & 28,8 juta jiwa & 11,34 \\
\hline
\end{tabular}

Sumber : BPS (Badan Pusat Statistik)

Usia harapan hidup penduduk Indonesia semakin meningkat dibandingkan dengan negara lain, dan diperkirakan mengalami aged population boom pada dua dekade permulaan abad 21 ini. Akibat dari fenomena yang telah dipaparkan sebelumnya, beban yang harus ditanggung oleh Negara semakin besar. Jumlah penduduk nonproduktif semakin bertambah dari tahun ke tahun, ketidakstabilan ekonomi pun salah satu faktor penyebab lansia yang sudah mempunyai keterbatasan fisik, semakin tidak berdaya.

Realita yang sama pun terbukti dari data yang dilansir dari UNDP. Pada tahun 1980 usia harapan hidup (UHH) 52,2 tahun dan jumlah lansia 7.998 .543 orang $(5,45 \%)$ maka pada tahun 2006 menjadi 19 juta orang $(8,90 \%)$ dan UHH juga meningkat $(66,2$ tahun). Pada tahun 2010 perkiraan penduduk lansia di Indonesia akan mencapai 23,9 juta atau 9,77 \% dan UHH sekitar 67,4 tahun. Sepuluh tahun kemudian atau pada 2020 perkiraan penduduk lansia di Indonesia mencapai 28,8 juta atau $11,34 \%$ dengan $\mathrm{UHH}$ sekitar 71,1 tahun. Rata-rata umur harapan hidup saat ini adalah 69 tahun (67 untuk lakilaki dan 71 untuk perempuan) (United Nations Population Division, 2010). Pada tahun 2050 diproyeksikan jumlah lansia akan meningkat menjadi 2,4 milyar orang. Sebelumnya jarang orang berusia 80 tahun atau lebih, tetapi kini kelompok lansia menjadi kelompok umur yang tumbuh paling cepat di dunia. Di wilayah yang lebih maju, sekitar 1 dari 4 orang saat ini berusia di atas 60 tahun. Pada tahun 2050, angka ini akan menjadi lebih 1 dari 3 orang. Di negara-negara berkembang 1 dari 20 orang kini berusia di atas 60 tahun, pada tahun 2050, angka ini akan menjadi 1 dari 9 orang. (UNDP, Human Development Report 2010). Tahun 2050, jumlah penduduk usia kerja yang ada untuk menanggung setiap orang yang berusia 65 tahun atau lebih tua akan menurun hingga setengahnya di seluruh dunia (World Population Highlight, 2010) dan akan menekan pembiayaan untuk pelayanan dukungan sosial dan pendanaan pensiun yang diselenggarakan pemerintah.

\section{PEMBAHASAN}

Penyandang Masalah Kesejahteraan Sosial yang menjadi fokus peneliti yaitu kelompok lanjut usia terlantar. Lansia terlantar 
adalah seseorang yang berusia 60 tahun atau lebih karena faktor-faktor tertentu tidak dapat memenuhi kebutuhan dasarnya baik secara jasmani, rohani, maupun sosialnya. Lansia Terlantar sendiri dapat dikategorikan sebagai keadaan sementara (transient lansia terlantar), suatu keadaan di mana lansia menjadi terlantar sementara karena krisis ekonomi, kebijakan pemerintah yang tak populis, dan bencana alam. Fenomena 'lansia terlantar sementara' di Indonesia cenderung terus bertambah saat krisis tahun 1997, kenaikan harga BBM, serta bencana alam seperti banjir, longsor, gempa dan tsunami beberapa waktu lalu.Di samping itu, terdapat kategori lansia terlantar kronis (chronic lansia terlantar) yang muncul akibat di luar faktor-faktor tersebut di atas. Namun, karena krisis ekonomi, dan fenomena lain ikut memperparah kehidupan mereka. Atas dasar itu, upaya penanganan lansia terlantar sementara lebih 'feasible' segera dilakukan dibanding lansia terlantar kronis. Upaya ini juga mengisyaratkan penanganan lansia terlantar sementara, karena di masa datang akan relatif lebih kompleks sehingga sulit dilakukan karena mengerucut pada lansia terlantar kronis.

Implementasi dari UU-RI No. 13 tahun 1998 yaitu dengan didirikannya Panti Sosial Tresna Werdha atau yang lebih dikenal sebagai Panti Jompo. Panti Sosial Tresna Werdha atau Panti Werdha merupakan tempat pelayanan sosial bagi orang lanjut usia dan termasuk ke dalam foster care. Menurut Armando Morales di dalam Budhi Wibhawa dkk, 2010: 81 foster care merupakan pelayanan yang bersifat tidak permanen, sehingga masih dimungkinkan untuk berhubungan dengan keluarga aslinya. Dilihat dari strategi pelayanan sosial, maka panti werdha termasuk ke dalam institutional based services, yaitu dalam pelayanan ini, individu yang mengalami masalah ditempatkan dalam lembaga pelayanan sosial. (Budhi Wibhawa dkk, 2010: 83). Sementara, implementasi dari UU-RI No. 11 tahun 2009 yaitu terpenuhinya kebutuhan dasar bagi lanjut usia di dalam panti; sandang, pangan, papan, kesehatan.
Berdasarkan Kebijakan dan Program Pelayanan Sosial Lanjut Usia di Indonesia (2003:2) penanganan permasalahan lanjut usia yang berkembang selama ini dikenal dengan melalui dua cara, yaitu pelayanan dalam panti dan luar panti. Pelayanan dalam Panti Sosial Tresna Werdha meliputi pemberian pangan, sandang, papan, pemeliharaan kesehatan, dan pelayanan bimbingan mental keagamaaan, serta pengisian waktu luang termasuk didalamnya rekreasi, olahraga dan keterampilan. Sedangkan pada pelayanan di luar panti para lanjut usia tetap berada di lingkungan keluarganya dengan diberikan bantuan makanan dan pemberdayaan di Bidang Usaha Ekonomis Produktif (UEP) melalui pendekatan kelembagaan sebagai investasi sosial dan merupakan bantuan yang diberikan kepada lanjut usia potensial yang kurang mampu.

Berdasarkan beberapa pendapat yang dikemukakan sebelumnya dengan adanya kehadiran panti werdha dapat membantu masyarakat dalam memberikan pelayanan terhadap para lanjut usia, sehingga kebutuhan para lanjut usia dapat terpenuhi dengan baik dan pada akhirnya akan menciptakan kesejahteraan lanjut usia dan keberfungsian sosial lanjut usia itu sendiri.

Berdirinya Panti Werdha diharapkan dapat menjadi solusi atas masalah sosial yang ada, salah satunya mengenai tingginya angka lansia terlantar. Dari tahun ke tahun jumlahnya cenderung meningkat. Pendirian panti werdha sebagai suatu sarana pelayanan kesejahteraan sosial bagi lansia yang terlantar. Kehadiran panti werdha membantu para lansia untuk mempertahankan kepribadiannya, memberikan jaminan kehidupan secara wajar baik secara fisik maupun psikologis. Sesuai dengan permasalahan lansia, pada umumnya penyelenggaraan panti werdha mempunyai tujuan antara lain agar terpenuhi kebutuhan hidup lansia, agar dihari tuanya dalam keadaan tentram lahir dan batin, dapat menjalani proses penuaannya dengan sehat dan mandiri. (Departemen Sosial RI, Petunjuk Pelaksanaan Panti Sosial Tresna Wredha Percontohan, 


\section{Jakarta, 1997)}

Pemenuhan kebutuhan yang dilakukan oleh panti werdha terhadap lansia tentu berbeda dengan kebutuhan individu pada umumnya; yang sehat secara fisik dan mental. Kebutuhan lansia memiliki spesifikasi sendiri terhadap kebutuhan hidupnya yang disebabkan oleh adanya proses penuaan dan berbagai kemunduran di dalam tahap kehidupan. Menurut Lowy Louis (1979: 44-45) bahwa kebutuhan lansia dibagi menjadi dua kebutuhan yaitu kebutuhan primer (utama) dan kebutuhan sekunder. Kebutuhan utama lansia dibagi menjadi 5 bagian yaitu; kebutuhan biologis/fisiologis yang meliputi kebutuhan makanan yang bergizi, seksual, pakaian dan perumahan (tempat berteduh), kebutuhan ekonomi yaitu berupa penghasilan yang memadai, kebutuhan kesehatan berupa kesehatan fisik, mental, perawatan, dan keamanan, kebutuhan psikologis yang meliputi kasih sayang, adanya tanggapan dari orang lain, ketentraman, merasa berguna, memiliki jati diri secara status yang jelas, serta kebutuhan sosial yaitu berupa perananperanan dalam hubungan antar pribadi dalam keluarga, teman-teman sesama lanjut usia dan hubungan dengan organisasi sosial.

Sedangkan kebutuhan sekunder bagi lanjut usia terdiri dari kebutuhan dalam melakukan aktivitas, kebutuhan dalam pengisian waktu yang luang dan rekreasi, kebutuhan yang bersifat kebudayaan seperti informasi, pengetahuan, keindahan dan lainlain, kebutuhan yang bersifat politis yaitu meliputi status perlindungan hukum, partisipasi, keterlibatan dalam kegiatankegiatan kemasyarakatan maupun negara/pemerintahan, serta kebutuhan keagamaan/spiritual seperti memahami akan makna kehadiran dirinya di dunia ini dan memahami hal-hal yang tidak diketahui/diluar kehidupan termasuk kematian.

Adanya kebutuhan hidup tidak hanya dimiliki oleh penduduk usia produktif saja, melainkan penduduk usia non-produktif yaitu lansia juga mempunyai hak untuk dapat memenuhi kebutuhan hidup yang dapat menunjang kehidupan dan kesejahteraan lanjut usia di dalam kehidupannya.

Ada beberapa faktor penyebab dimana lanjut usia menjadi terlantar, diantaranya; ketiadaan sanak keluarga, kerabat dan masyarakat lingkungan yang dapat memberikan bantuan tempat tinggal dan penghidupannya, kesulitan hubungan antara lanjut usia dengan keluarga dimana selama ini ia tinggal, ketiadaan kemampuan keuangan/ekonomi dari keluarga yang menjamin penghidupannya secara layak, kebutuhan penghidupannya tidak dapat dipenuhi melalui lapangan kerja yang ada, perkawinan anak sehingga anak hidup mandiri dan terpisah dari orangtua, serta urbanisasi yang menyebabkan lanjut usia terlantar. Selain itu, analisa penulis yang merupakan faktor penyebab tingginya angka lansia terlantar yaitu menurunnya fungsi tubuh yang menyebabkan kurangnya kemampuan lanjut usia tersebut dalam memenuhi kebutuhan hidupnya sendiri, bergesernya nilai dari keluarga besar (extended family) menjadi keluarga kecil / inti (nuclear family). Pada era globalisasi banyak anggota keluarga yang bekerja, sehingga keluarga atau lingkungan kurang mempunyai waktu memberikan pelayanan yang terbaik untuk para lanjut usia.

Di panti werdha terdapat pekerja sosial, bekerja sama dengan dokter, psikolog, dan pemuka agama. Pekerja sosial diibaratkan sebagai bunglon; di mana jika ia berdiam diri di suatu tempat, warna tubuhnya akan sama dengan benda yang ia sentuh. Analogi tersebut menggambarkan pekerja sosial yang dapat berperan ganda. Pekerja sosial harus menguasai berbagai bidang ilmu, disebut juga ekletik; tahu sedikit mengenai banyak hal. Peran profesi Pekerjaan Sosial menurut Budhi Wibhawa, Santoso T.R, dan Meilanny B.S (2010:33) secara garis besar berdasarkan ilmu pengetahuan, keterampilan, dan nilai-nilai pekerjaan sosial, yaitu meningkatkan kapasitas orang dalam mengatasi masalah yang dihadapinya, menggali dan menghubungkan sumber-sumber yang tersedia di sekitar klien, 
meningkatkan jaringan pelayanan sosial, mengoptimalkan keadilan sosial melalui pengembangan kebijakan sosial.

\section{PENUTUP}

Pada saat bekerja dengan individual, kelompok, keluarga, organisasi, dan juga komunitas, peran pekerja sosial bermacammacam berdasarkan ilmu pengetahuan dan kemampuan yang dimilikinya menurut Zastrow (2010: 70-72) antara lain sebagai enabler, broker, advocate, activist, mediator, negosiator, educator, initiator, empower, coordinator, researcher, group facilitator, dan public speaker. Akan tetapi, ketika seorang pekerja sosial berhadapan dengan klien yang sudah berusia lanjut maka pekerja sosial berperan sebagai broker. Pekerja sosial berperan untuk menghubungkan klien dengan sistem sumber yang dibutuhkan oleh klien dalam rangka meningkatkan keberfungsian sosial klien.

Pelayanan sosial yang diselenggarakan oleh pekerja sosial di bawah naungan Departemen Sosial Republik Indonesia memiliki empat tahap, diantaranya :

1. Persiapan. Hal-hal yang perlu dipersiapkan dalam proses pelayanan adalah menyangkut proses dari awal sampai dengan penerimaan yaitu :

Sosialisasi, merupakan pengenalan program pelayanan. Dilakukan oleh pegawai atau petugas ketika calon penerima manfaat dan keluarga datang ke tempat pelayanan/ petugas mendatangi calon penerima manfaat dan menjelaskan tentang pelayanan harian.

Penyebaran leaflet atau brosur pelayanan, Dilakukan oleh pegawai melalui penyuluhan-penyuluhan dimasyarakat.

Penyebaran informasi melalui media baik cetak maupun elektronik.

Pendekatan awal (kontak), merupakan proses penjalinan hubungan antara calon penerima manfaat dan masyarakat dengan lembaga pelayanan harian. Pada proses ini petugas mempertanyakan kesanggupan calon penerima manfaat. Memberi dukungan bila proses pelayanan dilaksanakan.

Kontrak, kontrak terjadi jika seseorang bersedia menjadi penerima manfaat. Calon penerima manfaat membuat permohonan untuk menjadi penerima manfaat. Calon penerima manfaat memenuhi persyaratan untuk yang ditentukan dan menandatangani suratsurat yang telah disepakati.

Pemahaman masalah (assesment), petugas menggali masalah-masalah kebutuhan yang dialami penerima manfaat. Dilakukan oleh petugas sebelum penerima manfaat menerima pelayanan. Petugas menggali harapan dan keinginan penerima manfaat berkaitan dengan pelayanan yang akan diterima nya. Petugas mengidentifikasi masalah dan kebutuhan penerima manfaat.

Rencana penanganan masalah. Petugas bersama penerima manfaat dan keluarganya menentukan alternatif yang akan dilakukan dalam rangka memenuhi kebutuhan.

2. Pelaksanaan Pelayanan.

Pelayanan yang diberikan secara umum adalah permakanan, pemeriksaan kesehatan, hiburan dan pengisian waktu luang, penyedian tempat yang sehat dan aman, pelayanan sosial, pelayanan data dan informasi, pelayanan transportasi dan pelayanan rujukan.

Petugas membuat jadwal pelaksanaan pelayanan.

Petugas mendampingi setiap pelaksanaan kegiatan.

Pengguna pelayanan bebas memilih kegiatan sesuai dengan keinginan dan kebutuhannya.

Petugas melaksanakan penyelenggaraan pelayanan yang diikuti oleh klien sesuai 
dengan jadwal dan tempat yang telah ditentukan.

3. Monitoring dan Evaluasi.

Pelaksanaan kegiatan dipantau dan dievaluasi oleh petugas. Hal-hal yang dipantau menyangkut jenis kegiatan, kendala kegiatan, faktor yang mendukung lancarnya kegiatan dan lain-lainnya. Perbaikan pelayanan dan perencanaan pelayanan di masa yang akan datang.

4. Terminasi.

Hal-hal yang menyebabkan tahap dimana penerima manfaat tidak lagi menjadi pengguna pelayanan. Petugas berperan dalam membantu pengambilan keputusan penghentian pelayanan.

Hal-hal yang menyebabkan terjadinya terminasi adalah penerima manfaat tidak mampu lagi mengikuti kegiatan-kegiatan pelayanan, penerima manfaat sakit dalam jangka waktu yang lama, permintaan penerima manfaat atau keluarga karena adanya sesuatu hal, penerima manfaat meninggal dan penerima manfaat memerlukan lembaga lain.

Tahap ini sama seperti proses intervensi pekerjaan sosial; di mana tahap pertamanya yaitu assessment, intervensi, plan of treatment, treatment, terminasi. Dalam kaitannya penerima manfaat memerlukan lembaga lain, petugas memberikan rujukan pada lembaga yang dibutuhkan. 